\title{
POSSIBLE TRIGGERING OF STRONG EARTHQUAKES IN A SEISMIC SEQUENCE DUE TO COULOMB STRESS CHANGES GENERATED BY THE OCCURRENCE OF PREVIOUS STRONG SHOCKS
}

\author{
E. E. PAPADIMITRIOU ${ }^{1}$, V. G. KARAKOSTAS ${ }^{1}$ AND A. B. BABA ${ }^{1}$
}

\begin{abstract}
Coulomb stress changes $(\triangle C F F)$ were calculated assuming that earthquakes can be modelled as static dislocations in an elastic half-space, and taking into account the coseismic slip in strong earthquakes. The stress change calculations were performed for strike, dip, and rake appropriate to the strong events considered. We evaluate if these chosen earthquakes brought a given strong subsequent event closer to, or farther from, failure. It was found that each of the subsequent strong events occurred in regions of increased calculated Coulomb stress before their occurrence. Moreover, the majority of smaller aftershocks also were located in areas of positive $\triangle C F F$. This indicates the probable triggering of the latter events, the foci of which are situated at nearby faults or fault segments.
\end{abstract}

KEY WORDS: seismic sequences; static stress changes; triggering.

\section{INTRODUCTION}

The broader Aegean area has experienced many destructive earthquakes as indicated from both instrumental data and historical information, some of them occurring very close in time. It is then of interest to examine if the stress changes associated with the occurrence of each one of them can advance the time of occurrence, i.e., to trigger subsequent ones. Earthquakes in a sequence generally are not independent (Scholz, 1990). Each one is affected by both tectonic loading and stress changes caused by prior events, especially by either great earthquakes or other shocks that occur nearby. From this point of view, the state of stress is studied.

Strong earthquakes that appeared to occur close in time indicate possible triggering of the following events by the previous one in the chain. Such observations have led several authors in the last decade to highlight the importance of fault interactions on the basis of physical models. Considerable research has been performed on earthquake triggering or delay due to changes in stress and this topic has been extensively discussed (e. g. Harris, 1998 and references therein). The points faced by researchers concern the possible triggering of subsequent earthquakes by earthquake-induced static or dynamic stress changes. The advantage of using changes in stress is that oftentimes, absolute values of stress are not known but stress change values can be calculated fairly readily from information about the geometry and slip direction of an earthquake rupture.

Coulomb stress change theory has been successfully applied to situations where faults were relaxed, the result of a negative change in Coulomb failure stress,. For cases where a fault is relaxed, or put into a stress shadow (Harris and Simpson, 1993, 1996; Deng and Sykes, 1997a,b), one can perform simple determinations of the approximate time that it should take for long-term tectonic loading to recover the static stress $\triangle C F S<0$ change. The Coulomb failure stress changes caused by main shock rupture effectively explain the aftershock distributions for the earthquakes studied, with some of the more distant events apparently being triggered by stress changes as low as 0.1 bar (Reasenberg and Simpson, 1992).

Portions of the San Andreas Fault were advanced about a decade in the cycle of great earthquakes by the 1992 Landers sequence of (Jaumt and Sykes, 1992). Not only do aftershocks appear to be triggered by such stress changes, but moderate seismicity prior to the Landers earthquake increased the potential for failure along most of the future Landers rupture zone, perhaps controlling the location of the later rupture (King et al., 1994). Such calculations for Southern California by Deng and Sykes (1997a, b) determine the distribution of large shocks of the past 185 years, moderate-sized shocks of the past few decades, and small and microearthquakes for the

1. Department of Geophysics, School of Geology, Aristotle University of Thessaloniki, GR54006 Thessaloniki, Greece e-mail: ritsa@geo.auth.gr,vkarak@geo.auth.gr, baba@lemnos.geo.auth.gr 
shorter time period for which they and their mechanisms are available.

In the present paper, we seek for possible triggering by calculating stress changes and applied these calculations to the study of earthquake interactions. For this reason, the coseismic stress changes associated with the occurrence of strong events, the first in the sequence are taken into account, following the procedure of Deng and Sykes (1997a). The present study covers the time interval 1976-2000, during which information on fault plane solutions of the stronger events $(M \geq 5.5)$ is available, since they are routinely analysed and distributed.

\section{METHODOLOGY}

The method used by Deng and Sykes (1997a) and applied by them to southern California was used in the present study. They consider stress to be a tensor quantity that varies in time and space and to be transmitted elastically, with the Earth approximated as a homogeneous half-space. Changes in stress associated with large earthquakes are calculated by putting certain coseismic displacements on ruptured fault segments in the elastic half-space and adding the changes in the components of the stress tensor together as they occur in time. Stress changes associated with both the virtual dislocations and actual earthquake displacements are calculated using a dislocation model of a planar fault surface, $\Sigma$, embedded in a homogeneous semi-infinite elastic medium, $\mathrm{i}$. e., a half-space with zero traction on the Earth's surface. Steketee (1958) showed that the displacement field $u_{k}\left(k^{\text {th }}\right.$ component of $\left.u\right)$ in a semi-infinite elastic medium for an arbitrary uniform dislocation, $U$, across a surface, $\Sigma$, can be determined from:

$$
u_{k}=\frac{U_{i}}{8 \pi \mu} \iint_{\Sigma} w_{i j}^{k} v_{j} d \Sigma
$$

where $\mu$ is the shear modulus, $v_{j}$ are the direction cosines of the normal to the dislocation surface, $U_{i}$ is the $i^{\text {th }}$ component of $U$, and $w_{i j}^{k}$ are six sets of Green's functions.

The displacements and strain fields caused by finite rectangular sources are obtained by integrating (1) (Okada, 1992; G. Converse, U. S. Geological Survey, unpublished report, 1973). The elastic stress $S_{i j}$ is calculated from strain $e_{i j}$ using Hooke's law for an isotropic medium

$$
s_{i j}=\frac{2 \mu v}{1-2 v} \delta_{i j} e_{k k}+2 \mu e_{i j}
$$

where $v$ is Poisson's ratio, and $\delta_{i j}$ is the Kronecker delta.

Earthquakes occur when the stress exceeds the strength of the fault. The closeness to failure was quantified using the change in Coulomb failure function $(\triangle C F F)$ (modified from Scholz, (1990)). It depends on both changes in shear stress $\Delta \tau$ and normal stress $\Delta \sigma$

$$
\Delta C F F=\Delta \tau+\mu^{\prime} \Delta \sigma
$$

Here $\mu^{\prime}$ is the apparent coefficient of friction. Both $\Delta \tau$ and $\Delta \sigma$ are calculated for a fault plane at the observing (field) point from the stress tensor described by (2). Change in shear stress $\Delta \tau$ is positive for increasing shear stress in the direction of relative slip on the observing fault; $\Delta \sigma$ is positive for increasing tensional normal stress. When compressional normal stress on a fault plane decreases, the static friction across the fault plane also decreases. Both positive $\Delta \tau$ and $\Delta \sigma$ move a fault toward failure; negative $\Delta \tau$ and $\Delta \sigma$ move it away from failure. A positive value of $\triangle C F F$ for a particular fault denotes movement of that fault toward failure (that is, the likelihood that it will rupture in an earthquake is increased).

The advantage of using changes in stress is that oftentimes, absolute values of stress are not known but values of stress change can be calculated fairly readily from information about the geometry and slip direction of an earthquake rupture. The exact details of geometry and slip also become less important the farther one goes from the rupture. 


\section{FOCAL PARAMETERS OF STRONG EVENTS}

Table 1 gives information on the fault plane solutions of earthquakes with $M \geq 6.5$ that occurred in the study area during 1976-2000. This is the time interval for which reliable fault plane solutions are routinely processed and distributed by Harvard University. We evaluate in the following if either the generation of these events triggered the occurrence of subsequent strong events, or if they have been triggered by previous strong events. To proceed in this evaluation, information on the fault plane solutions of the related strong events is needed. Since for events 1,8 and 12 of this table no information exists on fault plane solutions of strong events that occurred nearby, such examination is not feasible.

Table 1. Source parameters of large $(M \geq 6.5)$ earthquakes that occurred in the broader Aegean area during 1976-2000.

\begin{tabular}{|c|c|c|c|c|c|c|c|c|c|c|c|}
\hline & & & & \multirow[b]{2}{*}{ TIME } & \multirow[b]{2}{*}{$\varphi^{0} \mathrm{~N}$} & \multirow[b]{2}{*}{$\lambda 0_{\mathrm{E}}$} & \multirow[b]{2}{*}{$\mathbf{M}$} & \multicolumn{3}{|c|}{ Mechanism } & \multirow[b]{2}{*}{$\operatorname{Ref}$} \\
\hline & \multicolumn{3}{|c|}{ DATE } & & & & & Strike & Dip & Rake & \\
\hline 1 & 1976, & May & 11 & $00: 59: 18$ & 37.40 & 20.40 & 6.5 & 327 & 12 & 90 & 1 \\
\hline 2 & 1978, & June & 20 & $20: 03: 21$ & 40.71 & 23.27 & 6.5 & 278 & 46 & -70 & 2 \\
\hline 3 & 1979, & Apr. & 15 & $06: 19: 41$ & 42.09 & 19.21 & 7.1 & 317 & 15 & 90 & 3 \\
\hline 4 & 1980, & July & 9 & $02: 11: 57$ & 39.28 & 23.11 & 6.5 & 81 & 40 & -90 & 4 \\
\hline 5 & 1981, & Feb. & 24 & $20: 53: 37$ & 38.22 & 22.92 & 6.7 & 264 & 42 & -80 & 5 \\
\hline 6 & 1981, & Dec. & 19 & $14: 10: 51$ & 39.08 & 25.24 & 7.2 & 37 & 67 & -166 & 6 \\
\hline 7 & 1981, & Dec. & 27 & $17: 39: 13$ & 38.80 & 24.92 & 6.5 & 216 & 79 & 175 & 5 \\
\hline 8 & 1982, & Jan. & 18 & $19: 27: 25$ & 39.78 & 24.50 & 7.0 & 233 & 62 & -173 & 5 \\
\hline 9 & 1983, & Jan. & 17 & $12: 41: 30$ & 37.96 & 20.26 & 7.0 & 39 & 45 & 175 & 1 \\
\hline 10 & 1983, & Aug. & 6 & $15: 43: 52$ & 40.08 & 24.78 & 6.8 & 138 & 78 & -1 & 7 \\
\hline 11 & 1995, & May & 13 & $08: 47: 13$ & 40.15 & 21.68 & 6.6 & 240 & 45 & -101 & 9 \\
\hline 12 & 1997, & Nov. & 18 & $13: 07: 53$ & 37.58 & 20.57 & 6.6 & 8 & 31 & 162 & 7 \\
\hline
\end{tabular}

1. Papadimitriou (1993), 2. Soufleris and Stewart (1981), 3. Baker et al. (1997), 4. Papazachos et al. (1983), 5. Taymaz et al. (1991), 6. Papazachos et al. (1984), 7. Harvard solution.

Fault length and average displacement are two parameters necessary for the model application. Such information is not available from geological field observations for the earthquakes studied. Rupture zones of several strong earthquakes in Greece have been defined by the use of field observations of fault traces and by precise location of clusters of aftershocks or other relatively small earthquakes. Such data have been already used (Papazachos, 1989) to derive the following relations between the fault length, (in $\mathrm{km}$ ), and mean displacement, $u$ (in $\mathrm{cm}$ ), as a function of the moment magnitude $\mathrm{M}$ :

$$
\begin{aligned}
& \log L=0.51 M-1.85 \\
& \log u=0.82 M-3.71
\end{aligned}
$$

Therefore, these scaling laws were used to estimate the two parameters, $L$ and $u$, which are necessary for the application of the model (Table 2).

\begin{tabular}{|c|c|c|c|c|c|c|c|c|c|c|c|}
\hline \multirow{2}{*}{\multicolumn{2}{|c|}{ DATE }} & & \multirow[b]{2}{*}{ TIME } & \multirow[b]{2}{*}{$\varphi^{\circ} \mathrm{N}$} & \multirow[b]{2}{*}{$\lambda^{\circ} \mathrm{E}$} & \multirow{2}{*}{$\begin{array}{c}\mathrm{I} \\
(\mathrm{km})\end{array}$} & \multirow{2}{*}{$\underset{(\mathrm{cm})}{\mathbf{u}}$} & \multirow[t]{2}{*}{$\mathbf{M}$} & \multicolumn{3}{|c|}{ Mechanism } \\
\hline & & & & & & & & & Strike & Dip & Rake \\
\hline 1978, & May & 23 & $23: 34: 11$ & 40.70 & 23.29 & 10 & 11 & 5.8 & 265 & 40 & -83 \\
\hline 1979, & Apr. & 15 & $06: 19: 41$ & 42.09 & 19.21 & 56 & 130 & 7.1 & 317 & 15 & 90 \\
\hline 1980, & July & 9 & $02: 11: 57$ & 39.28 & 23.11 & 26 & 42 & 6.5 & 81 & 40 & -90 \\
\hline 1981, & Feb. & 24 & $20: 53: 37$ & 38.22 & 22.92 & 34 & 61 & 6.7 & 264 & 42 & -80 \\
\hline 1981, & Dec. & 19 & $14: 10: 51$ & 39.08 & 25.24 & 66 & 156 & 7.2 & 37 & 67 & -166 \\
\hline 1983, & Jan. & 17 & $12: 41: 30$ & 37.96 & 20.26 & 52 & 107 & 7.0 & 39 & 45 & 175 \\
\hline 1983, & Aug. & 6 & $15: 43: 52$ & 40.08 & 24.78 & 42 & 74 & 6.8 & 228 & 89 & -168 \\
\hline 1995, & May & 13 & $08: 47: 21$ & 40.15 & 21.68 & 30 & 42 & 6.6 & 243 & 45 & -97 \\
\hline
\end{tabular}

Table 2. Rupture models for strong earthquakes used for $\triangle C F F$ computation. 
The depths of the larger $(M \geq 6.0)$ earthquakes that occurred in the broader Aegean region, for which reliable determination of the focal parameters exists based either on waveform inversion or recordings of local seismic networks, range from 8 to $13 \mathrm{~km}$. From studies of aftershock sequences for which reliable determination of the aftershocks focal parameters also exists, it is evident that the majority of their foci are located in a seismogenic layer extending from a depth of 3 to $15 \mathrm{~km}$, some of them reaching a depth of $20 \mathrm{~km}$. Although precise depth determination does not exist for the smaller earthquakes that occurred in the study area, most of them are calculated as shallower than $15 \mathrm{~km}$. By considering all of the above information, the depth of the seismogenic layer in our calculations is taken to be in the range of $3-15 \mathrm{~km}$ for all of the strong events we modeled.

\section{STRESS CHANGES AND TRIGGERING OF SUBSEQUENT STRONG EVENTS}

Stress changes, i.e., values of $\triangle C F F$, are computed for the faulting type of the next stronger event in each seismic sequence. The coseismic displacements in the eight strong earthquakes in the broader Aegean Sea during 1976-2000 are computed in each case. The faults are simplified and approximated by rectangular shapes with two edges parallel to the Earth's surface. In each case, $\triangle C F F$ is calculated for a preferred fault plane solution, the one of the next event whose triggering is inspected. The shear modulus and Poisson's ratio are fixed as $33 \mathrm{GPa}$ and 0.25 , respectively. The apparent coefficient of friction, $\mu^{\prime}$, is fixed as 0.4 in the calculations, following Nalbant et al. (1998) who selected a value of 0.4, commenting that King et al. (1994) pointed out that even substantial variations from such a value do not greatly alter the distribution of Coulomb stresses around a fault. Deng and Sykes (1997a, b) extensively discussed this matter and found that their results were not very sensitive to changes in $\mu^{\prime}$. Stein et al. (1997) indicated that in general, the changes in absolute values of $\mu^{\prime}$ are not great.

Plate 1 shows the coseismic stress changes associated with the first strong event at a depth of $10 \mathrm{~km}$. This depth was chosen to be several kilometers above the locking depth in the model. In these plates, dark regions denote negative changes in Coulomb stress and inferred decreased likelihood of fault rupture. These regions are called stress shadows following the usage of Harris and Simpson $(1993,1996)$. Bright regions represent positive

$\triangle C F F$ and increased likelihood of rupture. The positive regions are called stress bright zones. It should be mentioned that stress is a tensorial, not a scalar, quantity. Thus shadow zones and bright zones must be viewed in the context of specific styles of fault slip, i.e., similar strike, dip, and rake. A particular location could be situated in a shadow zone for NE trending strike-slip faults, while it could be located in a bright zone for other styles of faulting. We will show that in each case the subsequent events occurred in bright zones, not in shadow zones.

Earthquake of 1978 (Thessaloniki, N. Greece) Plate 1A shows the coseismic stress changes associated with a strong $(M=5.8)$ event that struck the area around the city of Thessaloniki, on May 23, 1978. Focal mechanism solutions of the June 19 (M=5.3) event, and the main shock of this seismic sequence (June 20, 1978, M=6.5),

are also plotted in this figure. The mainshock is located in an area where the higher positive $\triangle C F F$ values were computed, while its foreshock in the borders between the bright and shadow zones.

Earthquake of 1979 (Monte Negro) The stress pattern due to the coseismic stress changes associated with the April 19, $1979(\mathrm{M}=7.1)$ main shock, along with the focal mechanism solutions of the two major earthquakes of that seismic sequence, are plotted in Plate 1B. Both aftershocks are located in a bright zone created by the generation of the main shock.

Earthquake of 1980 (Magnesia, central Greece) A bright zone of $\triangle C F F$ was created by the generation of the strong $(M=6.5)$ mainshock of this seismic sequence at the western part, where the largest aftershock $(M=6.1)$ occurred some minutes later (Plate $1 \mathrm{C})$. Whilst the second stronger aftershock $(M=5.6)$ occurred inside the shadow zone, probably at a barrier remained unbroken during the main rupture, about a month later, the third stronger aftershock $(M=5.3)$ occurred inside the western bright zone.

Earthquake of February 1981 (Alkyonides, Corinth Gulf) A strong earthquake of $M=6.7$ occurred in the study area on February 24, 1981 followed just a few hours later by a strong aftershock (February 25, 1981; M6.5).

On March 4, 1981 a strong event $(M=6.3)$ occurred at the eastern part, in an area where high positive $\triangle C F F$ values were computed due to the coseismic stress changes associated with the generation of the main shock (Plate 1D).

Earthquake of December 1981 (Northern Aegean) Plate 1E shows Coulomb stress changes associated with the December 19, 1981, large $(M=7.2)$ mainshock, along with focal mechanism solutions of the major earth- 

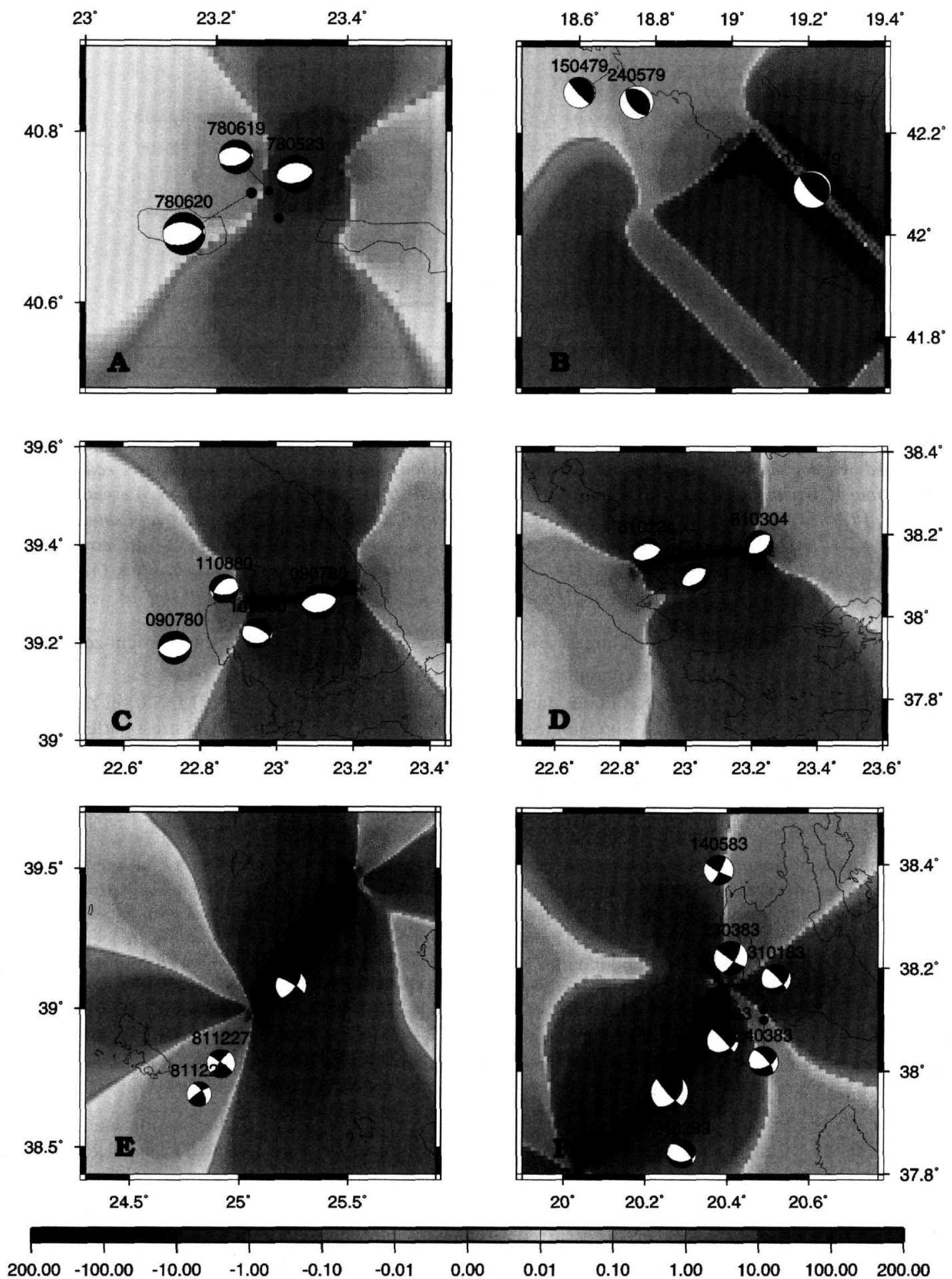

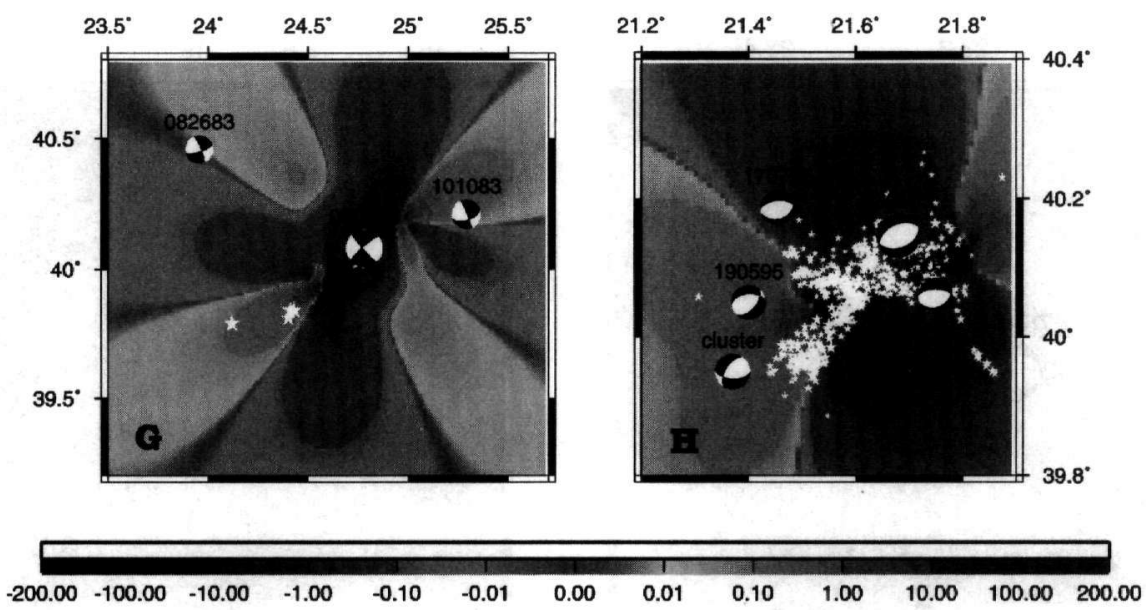

Plate 1. Coulomb stress changes due to the generation of strong events in the broader Aegean region during 19762000. The stress pattern is calculated for the faulting type of the next strong event in the sequence. Changes are denoted by color scale at bottom (in bars). Fault plane solutions are plotted as lower-hemisphere equal-area projections. Coseismic Coulomb stress changes associated with: $(A)$ the May 23, $1978(M=5.8)$ event. (B) the April 15, 1979 (M=7.1) Monte Negro main shock. (C) the July 9, 1980 (M=6.5) Magnesia main shock. (D) the February 24, 1981 (M=6.7) Alkyonides main shock. (E) the December 19, 1981, $(M=7.2)$ Northern Aegean main shock. (F) the January 17, 1981 (M=7.0) Kefalonia main shock. (G) the August 6, 1983, (M=6.8) Northern Aegean main shock. (H) the May 13, 1995 (M=6.6), Kozani main shock.

quakes of that seismic sequence. Both largest aftershocks occurred in a part of the created bright zone, where high positive values of $\triangle C F F$ were computed.

Earthquake of January 1983 (Kefalonia, Ionian Islands) The strong main shock $(\mathrm{M}=7.0)$ of this seismic sequence occurred on a dextral strike-slip fault (Scordilis et al., 1985). Plate 1F depicts the stress pattern after its occurrence, calculated for the fault plane solution of March 23, 1981 earthquake. This later event occurred in an area where values of positive $\triangle C F F$ are the highest. In the same plate all the available fault plane solutions of the stronger events of this sequence are also shown. Three out of five of them occurred in stress-enhanced zones.

Earthquake of August 1983 (Northern Aegean) This strong main shock occurred at a fault segment along the North Aegean Trough. Coseismic stress changes associated with its occurrence (Plate 1G) probably triggered the seismicity in the surrounding area. By asterisks the epicenters of aftershocks with $M \geq 4.5$ that occurred during September-November 1983 are denoted. It is worth noting that these epicenters are located either inside or very close to the calculated boundaries between stress shadow and stress-enhanced zones.

Earthquake of 1995 (Kozani, Northern Greece) Plate $1 \mathrm{H}$ shows the coseismic stress changes associated with this strong (M6.6) main shock. In the same plate the epicenters of precisely located aftershocks (Hatzfeld et al., 1997) are also shown. The stress field is computed according to representative fault plane solution (94/56/ -42) of the events constituting the western cluster of aftershocks (Papazachos et al., 1998). It is evident that this cluster occurred in a region with high values of positive $\triangle C F F$.

The above results show that static stress changes can lead to the identification of the location where the next strong event of a seismic excitation will occur, as well as the location of off-fault aftershocks. The higher positive $\triangle C F F$ values were calculated for these locations, where seismic activity occurs soon after (hours to days) the strong event which gives rise to the triggering. A limitation of the model efficiency, also noted by Cocco et al. (2000), concerns cases where some events occurred very close to the hypocenter of the main event, since rupture process details are needed, which usually are not available. On the other hand, the model efficiency has been proved in cases of nearby fault segments activation (Papadimitriou et al., 2001; among others).

Acknowledgements The stress tensors were calculated using a program written by J. Deng (Deng and Sykes, 1997a) using the DIS3D code of S. Dunbar and Erikson (1986) and the expressions of G. Converse. W. X. Du of 
Lamont helped us in using Deng's program. The GMT system (Wessel and Smith, 1991) was used to plot the figures. The authors would like to express their sincere appreciation to the anonymous reviewer for the contributive comments. This is Department of Geophysics contribution 551.

\section{REFERENCES}

BAKER, C., HATZFELD, D., LYON-CAEN, H., PAPADIMITRIOU, E. \& RIGO, A. 1997. Earthquake mechanisms of the Adriatic Sea and western Greece. Geophys. J. Int. 131, 559-594.

COCCO, M., NOSTRO, C. \& EKSTRÖM, G. 2000. Static stress changes and fault interaction during the 1997 Umbria-Marche earthquake sequence. J. Seismology 4, 501-516.

DENG, J. \& SYKES, L. R., 1997a. Evolution of the stress field in southern California and triggering of moderatesize earthquakes: A 200-year perspective. J. Geophys. Res. 102, 9859-9886.

DENG, J. \& SYKES, L. R., 1997b. Stress evolution in southern California and triggering of moderate-, small-, and micro-size earthquakes. J. Geophys. Res. 102, 24,411-24,435.

ERIKSON, L., 1986. User's manual for DIS3D: A three-dimensional dislocation program with applications to faulting in the Earth. Masters Thesis, Stanford Univ., Stanford, Calif., 167 pp.

HARRIS, R. A., 1998. Introduction to special session: Stress triggers, stress shadows, and implications for seismic hazard. J. Geophys. Res. 103, 24347-24358.

HARRIS, R. A. \& SIMPSON, R. W., 1993. In the shadow of 1857: An evaluation of the static stress changes generated by the M8 Ft. Tejon, California, earthquake. Eos Trans. AGU, 74(43), Fall Meet. Suppl., 427.

HARRIS, R. A. \& SIMPSON, R. W., 1996. In the shadow of 1857: The effect of the great Ft. Tejon earthquake on subsequent earthquakes in southern California. Geophys. Res. Lett. 23, 229-232.

HATZFELD, D., KARAKOSTAS, V., ZIAZIA, M., SELVAGGI, G., LEBORGNE, S., BERGE, C., GUIGUET, R., PAUL, A., VOIDOMATIS, PH., DIAGOURTAS, D., KASSARAS, I., KOUTSIKOS, I., MAKROPOULOS, K., AZZARA, R., DI BONA, M., BACCHECHI, S., BERNARD, P. \& PAPAIOANNOU, CH., 1997. The Kozani - Grevena (Greece) earthquake of May 13, 1995, revisited from a detailed seismological study. Bull. Seism. Soc. Am. 87, 463-473.

JAUMÉ, S. C. \& SYKES, L. R., 1992. Change in the state of stress on the southern San Andreas Fault resulting from the California earthquake sequence of April to June 1992. Science 258, 1325-1328.

KING, G. C. P., STEIN, R. S. \& LIN, J., 1994. Static stress changes and the triggering of earthquakes. Bull. Seism. Soc. Am. 84, 935-953.

NALBANT, S. S., HUBERT, A. \& KING, G. C. P. 1998. Stress coupling between earthquakes in northwestern Turkey and the north Aegean Sea. J. Geophys. Res. 103, 24469-24486.

OKADA, Y., 1992. Internal deformation due to shear and tensile faults in a half-space. Bull. Seism. Soc. Am. 82, 1018-1040.

PAPADIMITRIOU, E. E. 1993. Focal mechanism along the convex side of the Hellenic Arc and its tectonic significance. Boll. Geofis. Teor. Appl. 35, 401-426.

PAPADIMITRIOU, E. E., KARAKOSTAS, V. G. \& PAPAZACHOS, C. B. 2001. Rupture zones in the area of the 17.08.99 Ézmit (NW Turkey) large earthquake $\left(\mathrm{M}_{\mathrm{w}} 7.4\right)$ and stress changes caused by its generation, J. Seismology 5, 269-276, 2001.

PAPAZACHOS, B. C. 1989. Measures of earthquake size in Greece and surrounding areas. Proc. $1^{\text {st }}$ Scient. Cong., Geophys. Soc. Greece, Athens, April 19-21, 1989, 438-447.

PAPAZACHOS, B. C., PANAGIOTOPOUlOS, D. G., TSAPANOS, T. M., MOUNTRAKIS, D. M. \& DIMOPOULOS, G. CH., 1983. A study of the 1980 summer seismic sequence in the Magnesia region of central Greece. Geophys. J. R. astron. Soc. 75, 155-168.

PAPAZACHOS, B. C., KIRATZI, A. A., VOIDOMATIS, PH. S. \& PAPAIOANNOU, CH. A., 1984. A study of the December 1981 - January 1982 seismic activity in northern Aegean Sea. Boll. Geofis. Teor. Appl. 26, 101113.

PAPAZACHOS, B. C., KARAKOSTAS, B. G., KIRATZI, A. A., PAPADIMITRIOU, E. E. \& PAPAZACHOS, C. B. 1998. A model for the 1995 Kozani-Grevena seismic sequence. J. Geodynamics 26, 217-231.

REASENBERG, P. A. \& SIMPSON, R. W. 1992. Response of regional seismicity to the static stress change produced by the Loma Prieta earthquake. Science 255, 1687-1690.

SCHOLZ, C. 1990. The Mechanics of Earthquakes and Faulting. Cambridge University Press, Cambridge, 439pp. SCORDILIS, E. M., KARAKAISIS, G. F., KARAKOSTAS, B. G., PANAGIOTOPOULOS, D. G., COMNINAKIS, 
P. E. \& PAPAZACHOS, B. C. 1985. Evidence for transform faulting in the Ionian Sea. The Cephalonia island earthquake sequence of 1983. Pure Appl. Geophys. 123, 388-397.

SOUFLERIS, CH. \& STEWART, G., 1981. A source study of the Thessaloniki (N. Greece) 1978 earthquake sequence. Geophys. J. R. astron. Soc. 67, 343-358.

STEIN, R., BARKA, A. \& DIETERICH, J. 1997. Progressive failure on the North Anatolian fault since 1939 by earthquake stress triggering. Geophys. J. Int. 128, 593-604.

STEKETEE, J. A. 1958. On Voltera's dislocations in a semi-infinite elastic medium. Can. J. Phys. 36, 192-205.

TAYMAZ, T., JACKSON, J. \& McKENZIE, D., 1991. Active tectonics of the north and central Aegean Sea. Geophys. J. Int. 106, 433-490.

WESSEL, P. \& SMITH, W. H. F., 1995. New version of the Generic Mapping Tools released. EOS, Trans. Am. Geophys. U. 76, 329. 